\title{
Mulheres do meio rural: percepção quanto ao seu processo de trabalho no campo
}

RESUMO | Objetivo: compreender como as mulheres rurais percebem o seu processo de trabalho no campo. Método: Pesquisa de campo, descritiva, exploratória, com análise qualitativa, realizada no município de Cascavel/PR de janeiro a julho de 2018 com 29 mulheres. Resultados: Conforme dados coletados por meio de entrevista, com as mulheres trabalhadoras rurais, tendo como questão norteadora, "Me fale o que a senhora vê de bom no trabalho que realiza no campo", construímos 05 Discurso do Sujeito Coletivo (DSC), e destacado 08 ideias centrais, sendo elas: Ocupação; Sustento da família; União familiar; Interação social; Qualidade de Vida; Liberdade; Atividade prazerosa; Opção de vida. Conclusão: A pesquisa desvela que as mulheres trabalhadoras rurais entendem seu trabalho como uma ferramenta poderosa a partir de uma percepção integradora que ajusta não só o ponto de vista produtivo, como, também, nos aspectos social, ambiental e cultural.

Palavras-chaves: Mulheres Trabalhadoras; Agricultura; Percepção.

\begin{abstract}
Objective: to understand how rural women perceive their work process in the field. Method: Field research, descriptive, exploratory, with qualitative analysis, conducted in the municipality of Cascavel / PR from January to July 2018 with 29 women. Results: According to data collected through interviews, with women rural workers, having as a guiding question, "Tell me what you see in the work you do in the field", we built 05 Discourse of the Collective Subject (CSD), and 08 central ideas were highlighted, namely: Occupation; Family support; Family union; Social interaction; Quality of life; Freedom; Pleasurable activity; Life option. Conclusion: The research reveals that women rural workers understand their work as a powerful tool from an integrative perception that adjusts not only the productive point of view, but also in the social, environmental and cultural aspects.
\end{abstract}

Keywords: Women Working; Agriculture; Perception.

RESUMEN | Objetivo: comprender cómo las mujeres rurales perciben su proceso de trabajo en el campo. Método: Investigación de campo, descriptiva, exploratoria, con análisis cualitativo, realizada en el municipio de Cascavel / PR de enero a julio de 2018 con 29 mujeres. Resultados: De acuerdo a los datos recolectados a través de entrevistas, con trabajadoras rurales, teniendo como pregunta orientadora "Dime qué ves en el trabajo que haces en el campo", construimos 05 Discurso del Sujeto Colectivo (CDS), y Se destacaron 08 ideas centrales, a saber: Ocupación; Apoyo familiar; Unión familiar; Interacción social; Calidad de vida; Libertad; Actividad placentera; Opción de vida. Conclusión: La investigación revela que las trabajadoras rurales entienden su trabajo como una herramienta poderosa desde una percepción integradora que ajusta no solo el punto de vista productivo, sino también en los aspectos sociales, ambientales y culturales.

Palavras claves: Mujeres Trabajadoras; Agricultura; Percepción.

\section{Nelsi Salete Tonini}

Enfermeira. Doutora. Docente da Universidade Estadual do Oeste do Paraná, campus Cascavel/PR.

ORCID: 0000-0003-4704-7634

\section{Elizabeth Aparecida de Souza}

Enfermeira. Mestre. Docente da Universidade Estadual do Oeste do Paraná, campus Cascavel/PR.

ORCID: 0000-0002-0839-680x

\section{Leda Aparecida Vanelli Nabuco de Gouvêa}

Enfermeira. Doutora. Docente da Universidade Estadual do Oeste do Paraná, campus Cascavel/PR.

ORCID: 0000-0001-6641-7114

\section{Maristela Salete Maraschin}

Enfermeira. Mestre. Docente da Universidade Estadual do Oeste do Paraná, campus Cascavel/PR.

ORCID: 0000-0003-2184-5056

Recebido em: 30/07/2020

Aprovado em: 24/08/2020

\section{Sebastião Caldeira}

Enfermeiro. Doutor. Docente da Universidade Estadual do Oeste do Paraná, campus Cascavel/PR.

ORCID: 0000-0003-2827-1833

\section{Marcia Regina Silverio S. Barbosa Mendes}

Enfermeiro. Doutor. Docente da Universidade Estadual do Oeste do Paraná, campus Cascavel/PR.

ORCID: 0000-0002-1944-0482

\section{INTRODUÇÃO}

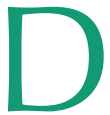
entre as transformações econômicas, sociais e políticas que ocorreram a partir do século XX pode-se destacar o avanço do trabalho da mulher nos setores produtivos para atender a demanda das organizações e para atender um desejo de crescimento profissional. Desta forma, a entrada da mulher no mercado de trabalho atende a dois anseios: o primeiro refere-se à necessidade da mulher de ampliar a renda familiar e por uma necessidade pessoal de crescimento; e a segunda pela necessidade das organizações. No Brasil, a partir da segunda metade do século XIX até depois da primeira grande guerra, a visão econômica e cultural se alterou, o que causou grande mudança no comportamento feminino. Com a industrialização e urbanização, a mulher passou a ter mais informações, ocupando maior espaço nas ruas, trabalhando e estudando. ${ }^{1}$ A colaboração da mulher no processo produtivo, não é recente, há registros que revelam historicamente a contribuição da mulher ao produto gerado da economia, que se faz presente desde a Revolução Industrial e substituíram a forma de trabalho artesanal. O marco da inserção da mão-de obra feminina foi a Primeira Guerra Mundial, pois a escassez de trabalhadores gerada pela guerra 
necessitava ser suprida, já que os homens estavam nas batalhas. Atualmente o que se percebe, é a crescente intensidade e a diversidade deste trabalho, pois as muIheres estão presentes em praticamente todos os setores da sociedade, inclusive os considerados masculinos, como o setor metal-mecânico, e, pode-se dizer, que na agricultura e agroindústria, estão realizando atividades que exigem mais do que tarefas repetitivas, ou seja, estão participando dos negócios da propriedade.

Afora as políticas públicas no País que procuram fomentar a agricultura familiar e aquelas que reconheceram direitos as mulheres rurais, como aposentadoria, licença maternidade, entre outras, sublinha-se que ainda há necessidade de ampliar o reconhecimento social e econômico delas. Em 2017, em Assembleia Geral das Nações Unidas, foi aprovada a "Década das Nações Unidas para a Agricultura Familiar (2019-2028)", conduzida pela Fundação das Organizações Unidas para a Alimentação e a Agricultura (FAO). Nesta campanha, entendeu-se que é preciso um ambiente regulatório favorável, considerando que a família e o campo representam uma unidade e que não desempenham só funções econômicas na economia rural, mas, sobretudo, desenvolvem funções ambientais, sociais e culturais que alavancam este setor da sociedade ${ }^{2}$.

A desigualdade baseada no gênero, em que as mulheres arcam com as consequências do não acesso a oportunidades políticas, econômicas e sociais é pauta internacional desde 2015, mediante um dos 17 Objetivos de Desenvolvimento Sustentável (ODS) da Organização das Nações Unidas (20152030), denominado "Alcançar a igualdade de gênero e empoderar todas as mulheres e meninas". Considera-se que divulgar necessidades de vários âmbitos desta parcela da população, de forma intensiva e extensiva é oportuno neste contexto histórico em que a informação que segue ainda é representativa no contexto rural no País: "embora sejam res-
A indagação central neste trabalho diz respeito: como estas mulheres, em uma região do oeste do estado do Paraná, em que predomina as grandes plantações de grãos, percebem sua vida no meio rural, na agricultura familiar. Assim sendo, o objetivo deste trabalho foi compreender como as mulheres rurais percebem o seu processo de trabalho no campo. ponsáveis por produzir mais da metade de todos os alimentos do mundo, muIheres são marginalizadas no meio rural. Apenas 30\% são donas formais de suas terras, $10 \%$ conseguem ter crédito e 5\% recebem assistência técnica" ${ }^{2}$.

Tais aspectos expressam-se em dados que indicam que a pobreza rural afeta mais mulheres, quando comparado com os homens. No ritmo das campanhas da FAO realizadas em parceria com a Organização das Nações Unidas (ONU), no Brasil, a principal delas é a intitulada "Mulheres Rurais, Mulheres com Direitos", sendo que em 2020 foi lançada sua quinta edição ${ }^{2}$.

Salienta-se que estudos nacionais, que corroboram com a condição de vida e trabalho da mulher rural mencionadas de forma geral acima, foram desenvolvidos em diversos contextos. As mulheres, contribuem significativamente não só para o desenvolvimento e renda familiar, mas, sobretudo estão relacionadas ao desenvolvimento das comunidades em que vivem ${ }^{3}$.

Como o meio rural não é homogêneo, por ser constituído no Brasil por diversas formações sociais, produtivas e culturais, é preciso provocar conhecimento dos contextos rurais em suas especificidades, de modo a compreender como ali se produzem as condições e os modos de vida das mulheres" ${ }^{\prime 4}$.

Pelo precedente, em que se verifica que há questões macroestruturais, mas também questões singulares que envolvem as mulheres rurais, esta pesquisa busca conhecer um grupo de mulheres rurais que vivem e trabalham na agricultura familiar. A indagação central neste trabalho diz respeito: como estas mulheres, em uma região do oeste do estado do Paraná, em que predomina as grandes plantações de grãos, percebem sua vida no meio rural, na agricultura familiar. Assim sendo, o objetivo deste trabalho foi compreender como as mulheres rurais percebem o seu processo de trabalho no campo. 
MÉTODOS

Pesquisa descritiva, exploratória, com análise qualitativa, realizada com mulheres que vivem nas áreas de abrangência nas Unidades de Saúde da Família da área rural do município de Cascavel/ PR, Região Oeste do Estado do Paraná, a coleta de dados ocorreu no período de janeiro a julho de 2018. Participaram do estudo 29 mulheres trabalhadoras rurais, todas esclarecidas sobre a pesquisa e, assinaram o Termo de Consentimento Livre e Esclarecido (TCLE). As entrevistas foram realizadas com hora marcada, sendo conduzidas pela questão norteadora: Me fale o que a senhora vê de bom no trabalho que realiza no campo?

Os dados coletados serão apresentados conforme o método do Discurso do Sujeito Coletivo (DSC), bem como, para a análise e interpretação dos dados. De acordo com, o discurso do sujeito coletivo é, em suma, uma forma ou um expediente destinado a fazer a coletividade falar diretamente ${ }^{5}$.

Essa técnica consiste em selecionar de cada resposta individual a uma determinada questão, as Expressões Chaves, que são trechos mais significativos destas respostas. A essas Expressões Chaves, correspondem Ideias Centrais, ou seja, a síntese do conteúdo manifestado nas Expressões Chave. Com esse material, são construídos os discursos-síntese, na primeira pessoa do singular, chamados de DSCs, onde o pensamento de um grupo ou coletividade aparece como se fosse um discurso individual, utilizando uma estratégia discursiva, o que torna mais clara dada apresentação social ${ }^{5}$.

A pesquisa foi aprovada pelo Comitê de Ética em Pesquisa da Universidade estadual do Oeste do Paraná (CEP/Unioeste), conforme parecer número 2.356.516 e CAAE 78560217.0.0000.0107. Respeitou-se as diretrizes da Resolução 466 de 2012.

\section{RESULTADOS E DISCUSSÕES}

Quanto às características sociode- mográficas, a faixa etária variou de 21 a 70 anos, com maior concentração nas faixas etárias de 31 a 35 e 46 a 50 anos, ambas com cinco mulheres $(17,24 \%)$, tendo como menores idades de 21 a 25 anos com dois casos $(6,89 \%)$ e as maiores idades de 66 a 70 anos com três muIheres (10,34\%). Quanto ao estado civil prevaleceu as mulheres que vivem em domicílio com companheiro ou cônjuge, ou seja, casadas e com união estável perfazendo o total de $25(86,20 \%)$. Para a cor da pele $26(89,65 \%)$ se declararam brancas e três $(10,34 \%)$ pardas. No que tange ao número de filhos, houve predomínio de dois filhos, totalizando 15 $(51,70 \%)$, entre quatro e seis filhos seis mulheres $(20,68 \%)$.

Apresenta-se os dados coletados por meio de entrevista, com as mulheres trabalhadoras rurais, em relação à questão, "Me fale que a senhora vê de bom no trabalho que realiza no campo?", construímos cinco DSC, foram destacadas oito ideias centrais, sendo elas: Ocupação; Sustento da família; União familiar; Interação social; Qualidade de Vida; Liberdade; Atividade prazerosa; Opção de vida. Segue abaixo os DSCs construídos, bem como as ideias centrais extraídas dos discursos os quais são discutidos e referenciados conforme literatura pertinente as temáticas.

\section{$1^{\circ}$ Discurso do Sujeito Coletivo}

Temos trabalho, essa é a parte positiva, não considero nada difícil, é bom ver a criação se multiplicar as plantas crescerem, você sabe o que está plantando e consumindo, a gente fala, que trabalhar no campo é uma opção de vida. Para quem gosta tudo é bom. É bom por que você tem o controle da sua alimentação.

Ideias Centrais: Ocupação; Opção de vida

Conforme o Discurso do Sujeito Coletivo, nota-se a importância do trabalho das mulheres. São as mulheres respon- sáveis pelo cuidado com a família, pela criação dos pequenos animais e dos produtos cultivados no quintal e no pomar, e contribui também com as tarefas consideradas produtivas, ou seja, com a produção de pecuária leiteira, de corte e de cria, Diante desses dados, podemos afirmar que essas mulheres também são responsáveis pela renda monetária e não atuam somente como ajudante, são trabalhadoras e merecem ser reconhecidas pelo seu trabalho tanto reprodutivo como produtivo.

E mesmo que estas atividades sejam prazerosas para as mulheres é marcante e acentuado o caráter obrigatório das mesmas, uma vez que não há a opção de escolha entre realizar ou não estas atividades ${ }^{6}$.

\section{$2^{\circ}$ Discurso do Sujeito Coletivo}

O positivo é a renda que entra em casa, você está levando o pão, e não passamos necessidade, se o marido não está ganhando, você tem de ganhar. Que é uma coisa boa, uma coisa positiva, você está se sentindo útil. Temos tudo aqui. Sou formado em História e Geografia, porém minha renda aqui é maior.

Ideias Centrais: Sustento da família;

As agricultoras em nível mundial contribuem ativamente para produção dos alimentos básicos, sendo responsáveis por mais de 50\% dos gêneros alimentícios produzidos. Nos países em desenvolvimento, por exemplo, sabe-se que a mulher responde por $43 \%$ da força de trabalho na agricultura, variando de 20\% na América Latina a 50\% na África Subsaariana. A edição 2010- 2011 da publicação "O Estado Mundial da Agricultura e da Alimentação", elaborada pela Organização das Nações Unidas para a Agricultura e a Alimentação (FAO), aponta que, se as mulheres tivessem os mesmos recursos de produção disponibilizados aos homens, elas poderiam aumentar a produtividade de suas 
lavouras de 20 a 30\%. E este dado fica mais alarmante quando vem acompanhado de outras projeções: se as condições entre homens e mulheres do campo fossem igualitárias, a produção agrícola dos países em desenvolvimento teria um acréscimo de 2,5 a 4\%, o que poderia reduzir de 12 a $17 \%$ o número de pessoas famintas no mundo ${ }^{7}$.

A presença das mulheres rurais na produção agrícola familiar é um fato. Mesmo na invisibilidade, não se pode negar que elas estão ocupando terras, plantando, colhendo e cultivando e tirando muitas vezes o sustendo da família com seu trabalho, conforme relato das participantes da pesquisa.

\section{$3^{\circ}$ Discurso do Sujeito Coletivo}

Sossego, menos robô, não tem agitação, há um sossego que não encontramos na cidade, não troco essa vida aqui por nada, estamos sempre em contato com a natureza, não temos aquela preocupação com os filhos, o que estão fazendo? Onde estão? Aqui eles estão juntos, trabalhando, mesmo que temos algumas desavenças, estão aqui, isso nos traz sossego, mesmo sendo trabalhoso a gente se diverte. Costumamos dizer que a noite, se você ficar quietinho, você escuta quase a grama cresce. Se relacionar bem com toda a vizinhança, é o que acontece, a gente tem alegria. Sempre tem um monte de gente que se visitam e recebemos com alegria, isso é amizade, as relações sociais no campo, é diferente, você visita mais o vizinho, você conversa mais com as pessoas.

Ideias Centrais: União Familiar, Interação Social

O entendimento da família como unidade de análise se justifica pela sua importância como agente integrador das relações sociais no interior das unidades de produção agrícola. No entanto,

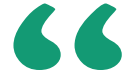

O entendimento da família como unidade de análise se justifica pela sua importância como agente integrador das relações sociais no interior das unidades de produção agrícola. No entanto, a família é um espaço de produção e de reprodução de valores cujos significados ultrapassam a lógica do parentesco e a racionalidade econômica. a família é um espaço de produção e de reprodução de valores cujos significados ultrapassam a lógica do parentesco e a racionalidade econômica ${ }^{8}$.

Assim, a família não deve ser entendida tão-somente como um grupo estruturado segundo as condições históricas e culturais que o cercam. É necessário também considerar o conjunto de valores que orientam e dão sentido às práticas sociais no interior da família já que ela agrega indivíduos por meio de uma rede de relações que inclui, como toda relação social, uma parte ideal, de pensamento, bem como de representação. A complexidade do processo de transformação do mundo rural brasileiro poderá ser melhor entendida quando as análises estiverem voltadas às relações entre os agentes sociais envolvidas na dinâmica de reprodução social. Isto significa incorporar a gama complexa das relações que definem e redefinem a família ${ }^{8}$.

Observa-se nos relatos que as agricultoras costumam visitar conhecidos, bem como recebem visitas, o que reitera o nosso entendimento de que "trabalhar coletivamente" é claramente distinto de "interagir socialmente". Toda essa dinâmica faz crer que não pode ser rejeitada a hipótese de que existe uma rede de interações sociais que favorece trocas consistentes entre as mulheres rurais e dessas com outros atores. A rede de relacionamentos gerada pelas agricultoras, com alguns interagindo mais intensamente que outros, mas sem se notar nenhum nível de isolamento A comunicação pode ter papel estratégico no processo de desenvolvimento circunscrito às mudanças das condições de vida das famílias, à medida que facilita trocas e aproximações entre as pessoas. Esse relacionamento, por sua vez, é parte do próprio ajuste social e tende a ser mais intenso, ou efetivo, em termos de qualidade, quanto mais consolidada for à rede de interações onde se realiza essa comunicação. A ideia é de estreita interdependência, funcionando como engrenagem de um círculo virtuoso ${ }^{9}$. 


\section{$4^{\circ}$ Discurso do Sujeito Coletivo}

Tudo é bom, mexer com a terra é ótimo, maravilhoso. Eu mexia só com pessoas, agora com a terra, nem se compara, não tem explicação. Trabalhei no exército durante 21 anos, parei e vim morar no sitio, é outra vida, não sei nem explicar. É fogão a lenha, a minha comida é diferente, tudo saudável. Você mesmo planta, a maioria do que você faz, as carnes você que produz, a gente não coloca agrotóxico, não tem nada de conservante, até meus exames melhoraram. Meu marido diz que acabou meu estresse. Para mim é prazeroso estar na terra, não é um trabalho difícil, é cansativo, mas sabe que você tem seu alimento, sem veneno.

Ideias Centrais: Prazeroso; Qualidade de Vida

A qualidade de vida do trabalhador reflete os fatores ambientais, que abrangem desde as condições precárias de trabalho até a forma de organização do trabalho, as relações humanas no ambiente de trabalho. Pode-se afirmar que as mulheres trabalhadoras rurais em questão consideram sua qualidade de vida, seja fisicamente ou moralmente, preservada no ambiente laboral, o que dificulta o aparecimento das doenças ocupacionais.

Apesar de haver inúmeras definições, não existe uma definição de qualidade de vida que seja amplamente aceita. Assim importante é não incluir apenas fatores relacionados à saúde, como bem-estar físico, funcional, emocional e mental, mas também outros elementos importantes da vida das pessoas como trabalho, família, amigos, e outras circunstâncias do cotidiano, sempre atentando que a percepção pessoal de quem pretende se investigar é primordial ${ }^{10}$.

A exemplo da qualidade de vida, determinados aspectos da nossa vida como a felicidade, amor e liberdade, mesmo expressando sentimentos e valores difíceis de serem compreendidos, não se tem dúvida quanto a sua relevância. Trata-se de um conceito para o qual até mesmo uma definição operacional é difícil de ser elaborada. Qualidade de vida, segundo o autor, vem sendo uma ideia largamente difundida na sociedade correndo-se o risco de haver uma banalização do assunto pelo seu uso ambíguo, indiscriminado ou oportunista ${ }^{11}$.

\section{$5^{\circ}$ Discurso do Sujeito Coletivo}

O bom de morar e trabalhar na roça é você sentir-se livre, dono de si, você é seu chefe. Se você trabalha, ganha, caso contrário não. Tudo é bom, liberdade é bom, você fazer o que gosta é bom. A gente não tem compromisso com horário.

\section{Ideias Centrais: Liberdade}

Nesse discurso fica claro o empoderamento das mulheres, entendido como o processo da conquista da autonomia, da autodeterminação, implicando, portanto, na libertação das mulheres das amarras da opressão de gênero, da opressão patriarcal. Neste sentido, o objetivo maior de ações voltadas para o empoderamento das mulheres é propiciar as condições para que elas possam questionar, desestabilizar e se organizar com vistas à erradicação da ordem patriarcal vigente ${ }^{12}$.

\section{CONCLUSÃO}

A pesquisa desvela que as mulheres trabalhadoras rurais entendem seu trabalho como uma ferramenta poderosa a partir de uma percepção integradora que ajusta não só o ponto de vista produtivo, como, também, nos aspectos social, ambiental e cultural que o trabalho da mulher representa no meio rural.

\section{Referências}

1. Medeiros, PF, Guareschi NMF. Políticas públicas de saúde da mulher: a integralidade em questão. Rev. Estudos Feministas, Florianópolis; 17(1): 296, janeiro-abril/2009.

2. Fao. Fundação das Organizaçães Unidas para a Alimentação e a Agricultura. Década das Nações Unidas para a Agricultura Familiar (2019-2028). Brasilia; 2019.

3. Siliprandi E, Cintrão R. As mulheres de Aquisição de Alimentos (PAA). Rev. Segurança Alimentar E Nutricional, 18(2), 13-32, 2011.

4. Gomes RCM, Nogueira C, Toneli MJF. Mulheres em Contextos Rurais: Um Mapeamento Sobre Gênero e Ruralidade. Psicol. Soc. vol.28 no.1 Belo Horizonte jan./abr. 2016.

5. Lefèvre F, Lefèvre AMC. 0 discurso do sujeito coletivo: um novo enfoque em pesquisa qualitativa (desdobramentos). 2.ed. Caxias do Sul: Educs; 2005. 6. Andrade RJ. et al. Relações sociais de gênero no meio rural brasileiro: a muIher camponesa e o lazer no início do século XXI no Brasil. Revista Brasileira de Educação Física e Esporte, São Paulo, v. 23, n. 1, p. 39-49, jan./mar. 2009.

7. Martins V. Fazendo gênero: Unisinos. Mulheres agricultoras: práticas e dis- cursos de resistência. Florianópolis, 25 a 28 de agosto de 2008. (Acessado em junho de 2020). Disponível em: http://www.fazendogenero.ufsc.br/8/sts/ ST3/Vera_\%20Martins_03.pdf.

8. Mattei L. A relevância da família como unidade de análise nos estudos sobre pluriatividade. Rev. Econ. Sociol. Rural v.45 n.4 Brasília out./dez. 2007. 9. Araújo $A B A$, Jeronimo CEM. Interações sociais, comunicação e desenvolvimento rural de agricultores familiares. Revista do Centro do Ciências Naturais e Exatas - UFSM, Santa Maria. v. 12 n. 12 ago. 2013, p. 2726- 2733. 10. Lunardelli G, Souza EF, Nodari TMSN. Qualidade de vida no trabalho: um estudo das trabalhadoras da indústria metal mecânica no meio oeste de Santa Catarina. Scientific Electronic Archives. Vol. 10 (4) August 2017. 11. Pereira EF, Teixeira CS, Santos A. Qualidade de vida: abordagens, conceitos e avaliação Rev. bras. Educ. Fís. Esporte, São Paulo, v.26, n.2, p.241-50, abr./jun. 2012.

12. Sardenberg CMB. Liberal vs liberating empowerment: a Latin American feminist perspective. Pathways Working Paper 7, Pathways of Women's Empowerment, Brighton, UK; IDS - Institute of Development Studies, 2009. 